\title{
Adaptable versus lightweight design of transitory dwellings
}

\author{
W. Debacker ${ }^{1}$, C. Henrotay ${ }^{2}$, W. P. de Wilde ${ }^{1} \&$ H. Hendrickx ${ }^{2}$ \\ ${ }^{1}$ Department of Mechanics of Materials and Constructions (MeMC), \\ Vrije Universiteit Brussel, Faculty of Engineering Sciences, Belgium \\ ${ }^{2}$ Department of Architecture (ARCH), Vrije Universiteit Brussel, \\ Faculty of Engineering Sciences, Belgium
}

\begin{abstract}
Optimisation of structures and materials is a justifiably popular engineering topic. Contemporary research is concentrated, among other things, into cost minimisation, structural efficiency and intelligence, in compliance with environmental and social preservation. This paper puts the accent on the time dependent aspect of constructions, such as the life cycle cost, the possibility to make (non-) structural changes and recycle or reuse of building materials. In search of an optimisation of this 'dynamic' efficiency of constructions, a design strategy has been developed at the Vrije Universiteit Brussel (dept. MeMC \& $\mathrm{ARCH}$ ). A logical question arises: can both types of optimization coexist? The answer is given through a realistic case study: transitory dwellings.

Keywords: adaptable, reuse, lightweight, optimization, transitory dwelling.
\end{abstract}

\section{Introduction}

A typical Western dwelling has an average life span of about a hundred years; a period which even the best futurologist won't burn his fingers on [1]. During this lapse of time households and habitats can change radically and repeatedly. Technical and social revolutions have already modified the meaning and the shape of the dwelling in the past decades. Which unforeseen defining moments shall housing deal with in the coming years?

Nowadays designers are faced, more than ever before, with the difficult task of giving form to dwellings for a period during which the composition of the 
household and the associated spatial rites will go through major changes. 'Flexibility', 'adaptability' and 'versatility' are the key elements to confront this unpredictable future! Hence a sustainable built environment requires dynamic design strategies in which no end states or final goals can be defined.

The "4Dimensional Design Strategy" (4D), invented by H. Hendrickx and H. Vanwalleghem includes this dynamic view on the built environment [2]. 4D is a guide to design multiple construction systems, all compatible to each other, by which a variety of adaptable and reusable construction elements can be composed. Each construction system is made of a minimum number of basic elements and a set of combination rules. They allow the conversion of each artefact to a different configuration, by means of adding, removing or transforming the basic elements which it is made of. It offers a high potential of recycling and (direct) reuse. The outcome can be compared with the 'Meccano' building set, which, in this view, encloses all materials and techniques, and is applicable to all scales. Hendrickx and Vanwalleghem proposed a set of standardisation rules, which they called a "generating form and dimensioning system". The generating system is a central concept in the design strategy, in the sense that it ensures full compatibility of form and dimensions between all basic elements. The rules are translated into a fractal model, based on basic forms, such as the square, the inner circle and its diagonal, and a dimensional range using the operator "multiply or divide by 2 ".

\section{Flemish social housing: a face lift!}

Similar to our neighbouring countries, Belgium is experiencing a shortage of adequate (social) habitats. Many dwellings do not meet the contemporary standards anymore. Subsequently the Flemish government currently invests in building a thousand new houses [3]. It seeks ecological solutions with the intention of lowering the "total life cycle cost". Flexible building methods are highly coveted, since the dwellers group is very heterogeneous (culture, composition, age and social background) and the demand of a social habitat is still growing. Reuse of elements and the possibility to make structural and nonstructural changes is essential to enhance the possibilities of the social dwellings.

In anticipation of the construction of new dwellings and the reinstatement of existent ones, qualitative and low cost temporary housing is required. Transitory habitats will be offered to (re)allocate underprivileged people for a span of 3 to 6 months - exceptionally 1 year [4]. Since the Flemish Ministry of social housing is carrying out a big scale reconditioning of its entire heritage - an ongoing project - the idea has popped up to make use of re-movable transitory habitats that are easily transported from one place to another. Flexible building methods, which are compatible to the existing transportation standards, are thus also indispensable for short term solutions.

Transitory housing will not offer any structural answer to the Belgian housing problematic. Nevertheless it is a way to counter the process of social disintegration which comes along in becoming homeless [4]. 


\section{The design of transitory dwellings}

\subsection{Design constraints}

In partnership with the steel producer Arcelor and thanks to the input of the Flemish Ministry of Social Housing, the departments of Architecture (ARCH) and Mechanics of Materials and Constructions (MeMC) of the Vrije Universiteit Brussel have designed a construction kit for temporary constructions. All base elements are interchangeable and resizable, making them the construction elements for a multitude of configurations, such as various dwelling types. A list of the main design constraints is given below:

The temporary necessity of the dwellings imposes a reversible impact on the environment. The structure and its components have to be assembled, dismantled and carried away without leaving permanent traces which can harm the construction site.

An effective transport method in compliance with (inter)national transport regulations is required. Unused transport space is to be minimised and 'intermodal' possibilities is to be maximised.

The structure of the transitory dwelling has to be easily assembled and dismantled in a short period of a few days to cope with changing situations, such as a succession of dwellers and reconditioning of an existing habitat, or unforeseen events, such as a flood or a fire which makes an existent dwelling temporary inhabitable.

- Frequent assembling, dismantling and transporting will make some parts vulnerable to accidental charges and deterioration, such as corrosion and fatigue. Besides an intelligent choice of the building material, several maintenance procedures (during a life cycle of 20 years) should be taken into account.

- A minimum of comfort and safety has to be provided. Performances concerning fire safety, thermal and acoustic insulation, hygiene, heating, cooling and ventilation are well defined by the Flemish Housing Society [3].

\subsection{Composition of the construction kit}

Based on the previously mentioned constraints a construction kit was designed. It is composed of 4 major types of simple construction elements:

1. bearing frames (end and intermediate frames)

2. horizontal girders (base structure and girders)

3. sandwich panels (floor, roof, side and end walls)

4. dry connections (bolts and twistlocks)

Each of them is made of 'neutral' base elements such as profiles (one-dimensional), plates (two-dimensional), hollow and plain volumes (three-dimensional). Once they are assembled together they acquire a 
constructive meaning! Thanks to the generating system, each base element is compatible with any other - and thus interchangeable. The above mentioned construction components are hereby resizable and transformable as required using a minimum of base elements.

Since sanitary facilities and a kitchen had to be incorporated into the dwellings, a fifth hybrid construction element type is introduced, i.e. the wet cell. It is composed of the 4 former types of construction elements and encloses the necessary services to allow the daily rituals. These (small) prefabricated spaces will move up the construction speed, since they only need to be plugged into the interior surrounding where electricity and water supply is available.

The proposed dwellings (Fig. 5) are too big to transport them in one piece. To allow 'intermodal' transport (train, truck and inland waterway) the design was oriented to a 20' ISO container wherein the bearing frames, horizontal profiles and sandwich elements of 5 equivalent 20' units are compacted to each other (Fig. 1). Two wet cells fit likewise into a 20' ISO container. The ISO container can be composed of elements of the kit or a second hand cargo container can be reconditioned. Following these design tips transport and storage cost will drop significantly.

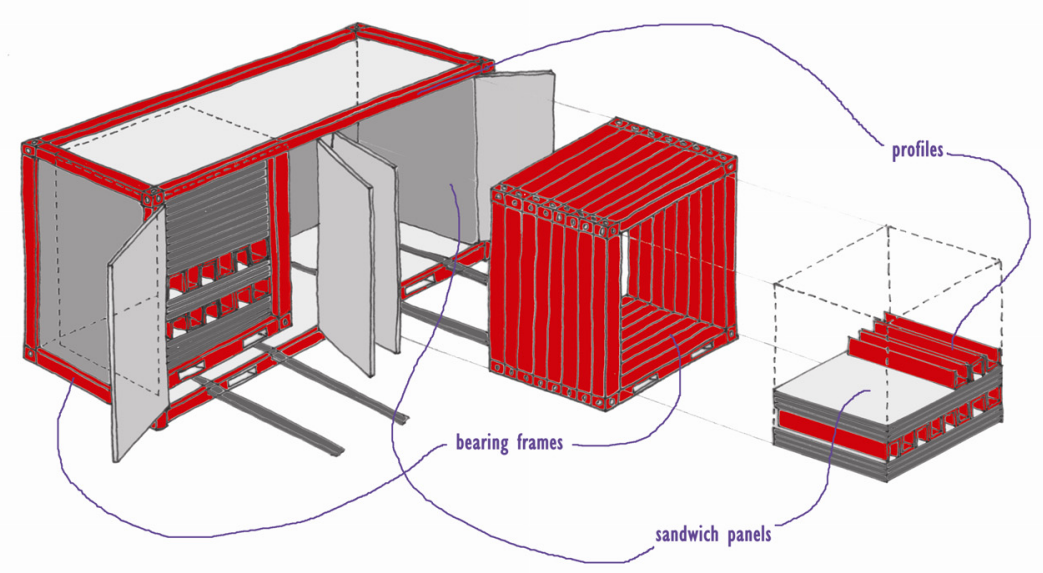

Figure 1: Composition of the construction kit during transport.

\subsection{Design catalogues}

An aid to the development of the construction kit was to draw up design catalogues for the 4 major types of construction parts. Each of them was decomposed into design variables:

1. bearing frame: thickness of plate; length, width, depth and sectional form of profile, material type; form of ISO corner element; way of composition of the frame (monolithic - composite); way of connecting. 
2. horizontal girder: thickness of plate; length, width, depth and sectional form of profile, material type; way of composition of girder (monolithic - composite); way of connecting.

3. sandwich element: thickness and form of faces, material type of faces and insulation, thickness of insulation; length and width of the sandwich panel; opening type and form; way of composition of sandwich element (monolithic - composite); way of connecting.

4. dry connections: connection type; bearing section (diameter) and length of connection, number of elements, material type.

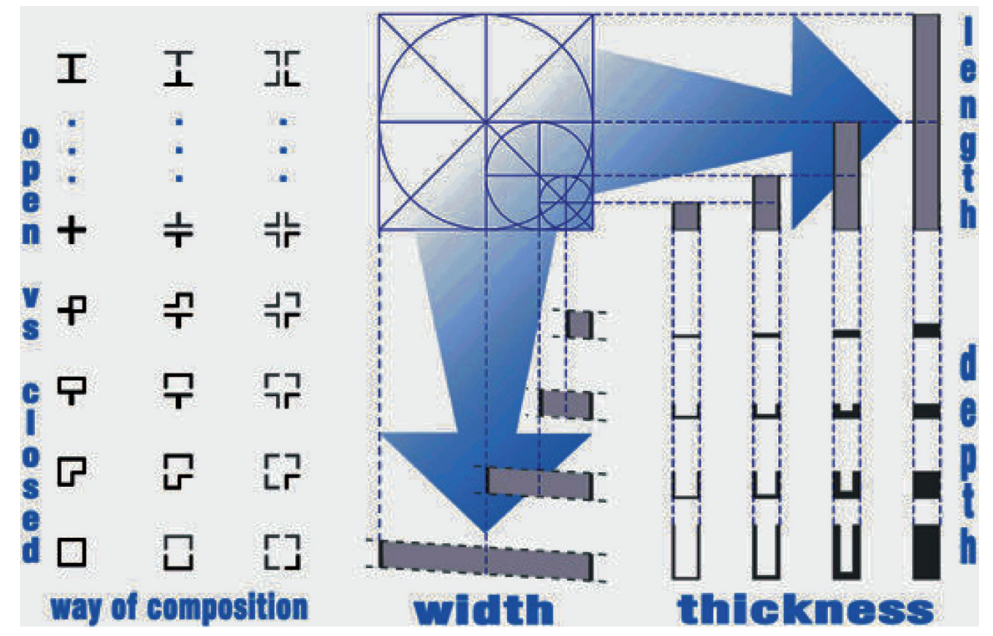

Figure 2: A partial design catalogue of steel horizontal girders.

Once the variables determined, series were drawn up for each of them. First extreme 'values' were considered, after which intermediate values were depicted through interpolation and/or combination of these outer points. This action was done with the help of the fractal model of the generating system. An example is illustrated in Fig. 2. A theoretical design catalogue is thus established, combining and juxtaposing elements. The emphasis has been put on 'theoretical', as in practice not all combinations are possible or technically sound. This means that they are erased in the practical catalogue.

\subsection{Dry connections}

The construction kit includes two kinds of dry connections, i.e. "bolts et al" and "twistlocks et al". The idea is to use the former for the composition of the major construction parts, such as the girders and the frames. The latter are used for frequent combinations between elements, such as the assembly of construction elements on the field. The twistlock is a well known device in the field of international transportation, since it is employed to secure containers during stacking (in cargo ships or at the docks) and the connection with the bodywork of trailers. In these cases vertical connections are made with either the top or bottom corner fitting of containers. 
It is our intention to improve the existing twistlock system by adding horizontal connection possibilities. This means however that the corner fittings and twistlocks are to be reinvented. The existing bottom and top corner fittings are integrated in one volume with multiple connection possibilities: twistlocks, bolts, plugs et al (Fig .3) Combinations with other base elements are possible via the 6 faces. The 'revisited' twistlock (Fig. 4) is composed of a steel wire whereon different plates are fixed. The head of the twistlock is removable and can be replaced by an other one that fits in the desired hole of the polyvalent ISO corner element. By doing so, vertical and horizontal connections are made possible using the same device. To open or close, the handle must only turn a quarter of a circle.

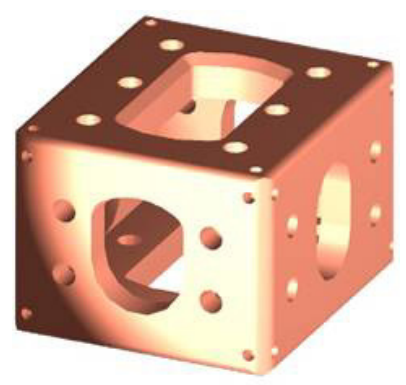

Figure 3: Polyvalent corner

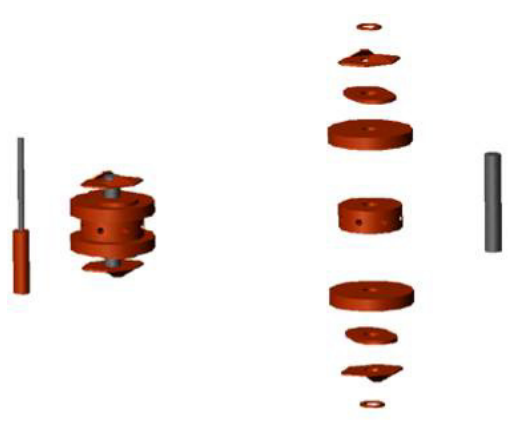

Figure 4: Adaptable twistlock. fitting.

The features of these dry connection elements endorse the "4dimensional aspects' of the construction kit. Besides the ease of assembly and dismantling, the maintenance of construction parts and the reuse of components in other constructions are made possible. Damaged basic elements can be reused allowing small transformations, even in fields where the structural, i.e. load bearing properties, are less important (furniture, window frames...). Hence the "total life cycle cost" of the elements will decrease. A good design of the connection is thus imperative.

\section{Structural analysis}

During the design of the transitory dwellings the question popped up if the 4D strategy could be coupled with structural optimization? Is it possible to present the user of the kit a minimum of compatible basic elements which can be assembled into multiple lightweight components and still meet the normative strength, stiffness and stability regulations? The weight of the components will determine the way and the facility of handling during assembly and dismantling.

A catalogue of structural U-profiles generated by the fractal model (Ugen) was entered into finite elements software. By using this tool the minimal 
dimensions of a steel skeleton of 4 different dwelling configurations (Fig. 5) were determined. The study was restricted to static analysis and characteristic local charges.
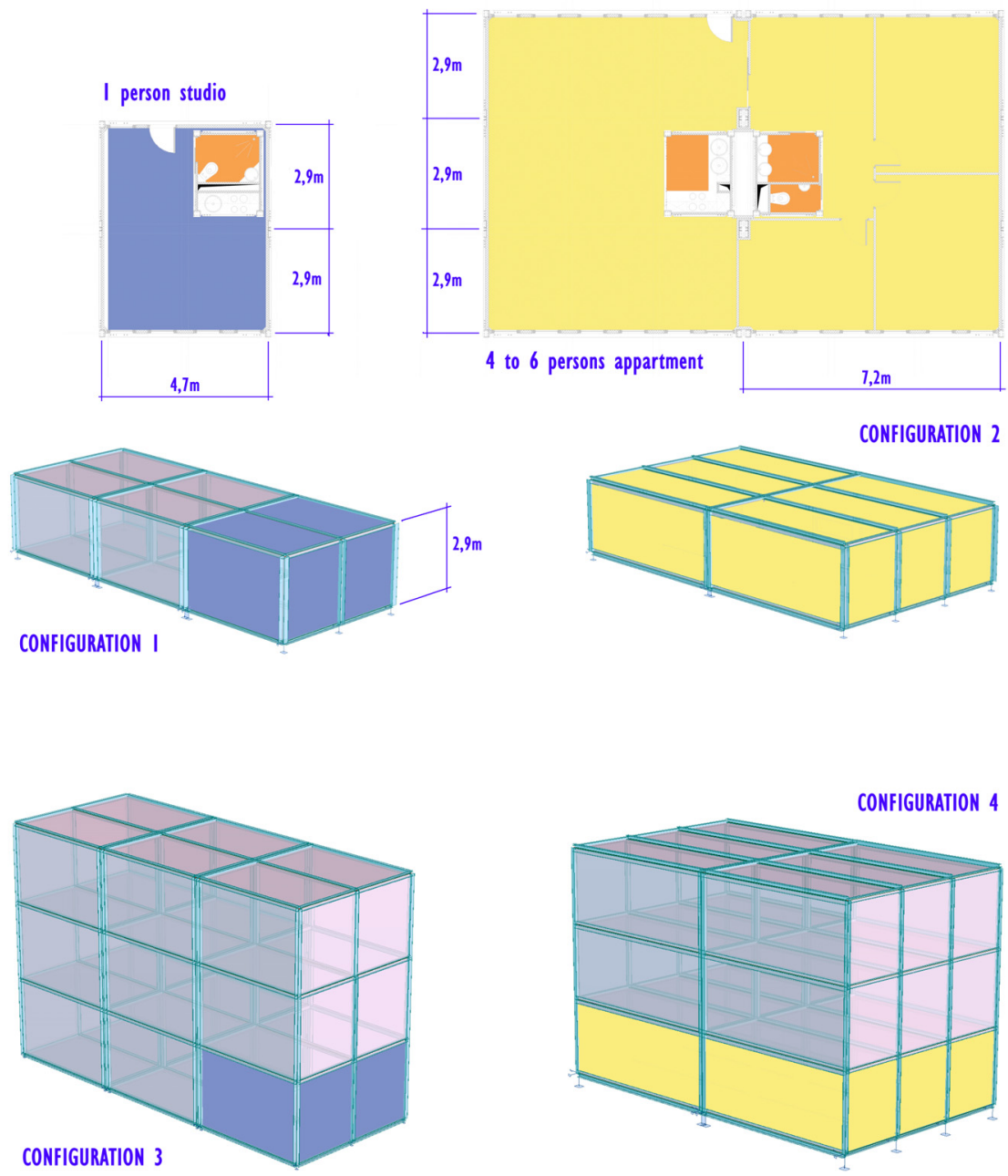

Figure 5: Four different dwelling configurations made with the same construction kit.

A comparison between the Ugen-profiles and typical U-sections available on the market (UAP, UPE, UPN) gives an idea about the relative performance of the structural properties of the construction kit. A summary is given in the following table.

The above mentioned U-profiles fulfil all structural constraints on the construction. The weight of (too) slender sections was penalised with the extra weight of the compulsory stiffeners to prevent local buckling. 
Table 1 shows that for the 4 scenarios the Ugen-sections compete with the U's currently available on the market. The choice of only considering open sections was strictly a technical /logistical one. Compared to tubular sections, which have better structural properties, U-profiles are easier to connect and disconnect.

Table 1: Optimal U profiles for the 4 dwelling configurations.

\begin{tabular}{|c|c|c|c|c|c|c|c|c|c|}
\hline \multirow[b]{2}{*}{ CONFIG. 1} & \multirow[b]{2}{*}{$\begin{array}{l}\text { length } \\
\text { (m) }\end{array}$} & \multicolumn{2}{|c|}{ Ugen } & \multicolumn{2}{|c|}{ UAP } & \multicolumn{2}{|c|}{ UPE } & \multicolumn{2}{|c|}{ UPN } \\
\hline & & type & $\begin{array}{c}\text { mass } \\
(\mathrm{kg})\end{array}$ & type & $\begin{array}{c}\operatorname{mass} \\
(\mathrm{kg})\end{array}$ & type & $\begin{array}{c}\text { mass } \\
(\mathrm{kg})\end{array}$ & type & $\begin{array}{c}\text { mass } \\
(\mathrm{kg})\end{array}$ \\
\hline FRAME: vertical & 2,9 & $153 \times 153 \times 3,6$ & 40,0 & 150 & 51,9 & 160 & 49,2 & 160 & 54,3 \\
\hline FRAME: horizontal & $2 \times 1,98$ & $153 \times 153 \times 4,8$ & 38,1 & 150 & 35,5 & 160 & 33,7 & 160 & 37,1 \\
\hline GIRDER & 2,5 & $153 \times 153 \times 3,6$ & 36,8 & 150 & 45,4 & 160 & 43,1 & 160 & 47,5 \\
\hline
\end{tabular}

\begin{tabular}{|c|c|c|c|c|c|c|c|c|c|}
\hline \multirow[b]{2}{*}{ CONFIG. 2} & \multirow[b]{2}{*}{$\begin{array}{l}\text { length } \\
(\mathrm{m})\end{array}$} & \multicolumn{2}{|l|}{ Ugen } & \multicolumn{2}{|c|}{ UAP } & \multicolumn{2}{|c|}{ UPE } & \multicolumn{2}{|c|}{ UPN } \\
\hline & & type & $\begin{array}{c}\text { mass } \\
(\mathrm{kg})\end{array}$ & type & $\begin{array}{c}\text { mass } \\
(\mathrm{kg})\end{array}$ & type & $\begin{array}{c}\text { mass } \\
(\mathrm{kg})\end{array}$ & type & $\begin{array}{c}\text { mass } \\
(\mathrm{kg})\end{array}$ \\
\hline FRAME: vertical & 2,9 & $153 \times 153 \times 4,8$ & 55,6 & 150 & 51,9 & 160 & 49,2 & 160 & 54,3 \\
\hline FRAME: horizontal & $3 \times 2,0$ & $2 \times[153 \times 153 \times 3,6]$ & $2 \times 27,6$ & 250 & 68,1 & 270 & 69,7 & 260 & 74,7 \\
\hline GIRDER & 2,5 & $153 \times 153 \times 3,6$ & 36,8 & 150 & 45,4 & 160 & 43,1 & 160 & 47,5 \\
\hline
\end{tabular}

\begin{tabular}{|c|c|c|c|c|c|c|c|c|c|}
\hline \multirow[b]{2}{*}{ CONFIG. 3} & \multirow[b]{2}{*}{$\begin{array}{c}\text { length } \\
(m)\end{array}$} & \multicolumn{2}{|c|}{ Ugen } & \multicolumn{2}{|c|}{ UAP } & \multicolumn{2}{|c|}{ UPE } & \multicolumn{2}{|c|}{ UPN } \\
\hline & & type & $\begin{array}{c}\text { mass } \\
(\mathrm{kg})\end{array}$ & type & $\begin{array}{c}\text { mass } \\
(\mathrm{kg})\end{array}$ & type & $\begin{array}{c}\text { mass } \\
(\mathrm{kg})\end{array}$ & type & $\begin{array}{c}\text { mass } \\
(\mathrm{kg})\end{array}$ \\
\hline FRAME: vertical & 2,9 & $229 \times 229 \times 3,6$ & 63,4 & 175 & 61,5 & 180 & 54,4 & 180 & 63,3 \\
\hline FRAME: horizontal & $2 \times 1,98$ & $153 \times 153 \times 4,8$ & 38,0 & 150 & 35,5 & 160 & 33,7 & 160 & 37,1 \\
\hline GIRDER & 2,5 & $153 \times 153 \times 3,6$ & 36,8 & 150 & 45,4 & 160 & 43,1 & 160 & 47,5 \\
\hline
\end{tabular}

\begin{tabular}{|c|c|c|c|c|c|c|c|c|c|}
\hline \multirow[b]{2}{*}{ CONFIG. 4} & \multirow[b]{2}{*}{$\begin{array}{l}\text { length } \\
\text { (m) }\end{array}$} & \multicolumn{2}{|l|}{ Ugen } & \multicolumn{2}{|c|}{ UAP } & \multicolumn{2}{|c|}{ UPE } & \multicolumn{2}{|c|}{ UPN } \\
\hline & & type & $\begin{array}{c}\text { mass } \\
(\mathrm{kg})\end{array}$ & type & $\begin{array}{c}\text { mass } \\
(\mathrm{kg})\end{array}$ & type & $\begin{array}{c}\text { mass } \\
(\mathrm{kg})\end{array}$ & type & $\begin{array}{c}\text { mass } \\
(\mathrm{kg})\end{array}$ \\
\hline FRAME: vertical & 2,9 & $229 \times 229 \times 4,8$ & 84,2 & 200 & 72,7 & 200 & 66,0 & 200 & 72,8 \\
\hline FRAME: horizontal & $3 \times 2,0$ & $2 \times[153 \times 153 \times 3,6]$ & $2 \times 27,6$ & 250 & 68,1 & 270 & 69,7 & 260 & 74,7 \\
\hline GIRDER & 2,5 & $153 \times 153 \times 3,6$ & 36,8 & 150 & 45,4 & 160 & 43,1 & 160 & 47,5 \\
\hline
\end{tabular}

\section{Conclusions}

The combination of structural optimization and the 4D design strategy offers a double benefit! Considering the fact that the volume of the structural components is minimised, the initial material cost will drop. In addition the construction, maintenance and demolition cost will be minimal since the principle of reusing, easily assembling and dismantling is incorporated into the design. The result is highly interesting: a minimisation of the construction cost and the construction 
energy over the whole life cycle of the artefact and its components. Although this study has been done for transitory dwellings, this design philosophy can be extrapolated to other constructions as well (fig. 6).

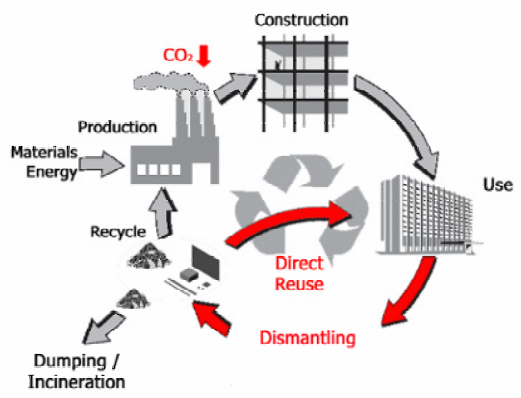

Figure 6: Proposed life cycle model of a construction.

\section{References}

[1] Leupen B, Kader en generieke ruimte - Een onderzoek naar de veranderbare woning op basis van het permanente, Uitgeverij 010, Rotterdam, 2002, 254p.

[2] Hendrickx H., Solutions derived from natural processes harmonising nature and material culture. Proc. of the $1^{\text {st }}$ Conf. on Design and Nature 2002. Comparing Design in Nature with science and engineering, ed. C.A. Brebbia \& L.J. Sucharov, Wessex Institute of Technology, United Kingdom and P. Pascolo, Universita degli di Udini, Italy, 10p. 2002.

[3] WTCB / VHM, ABSW 2003: Algemeen Bestek voor de Sociale Woningbouw: Prestatiebestek, Vlaamse Huisvestingsmaatschappij, Brussels, december 2003, 152p.

[4] Roggemans M-L et al, Transit-huisvesting: Vangnet en Springplank: Evaluatie van en perspectieven voor transit-huisvesting in het Brusselse Hoofdstedelijk Gewest, Koning Boudewijnstichting, Brussel, 1994, 82p. 